\title{
Interface entre patrimônio geomorfológico e cultural no Pampa: discussão a partir do Cerro do Jarau e do Cerro dos Porongos (Rio Grande do Sul, Brasil)
}

\author{
Interface betwen geomorphological and cultural heritage in the \\ Pampa: discussion from Cerro do Jarau and Cerro dos \\ Porongos (Rio Grande do Sul, Brazil)
}

\author{
Tanice Cristina Kormann, Fundação Estadual de Proteção Ambiental Henrique Luiz Roessler - RS e \\ Departamento de Geociências, Universidade Federal do Rio Grande do Sul, Brasil, \\ tanice.kormann@gmail.com \\ (1) https://orcid.org/0000-0003-4897-5811 \\ Monica Marlise Wiggers, Secretaria de Estado da Cultura do Rio Grande do Sul, Brasil, \\ moni_lise@yahoo.com.br
}

https://orcid.org/0000-0002-2108-8764

\begin{abstract}
Resumo: $O$ presente artigo objetiva discutir a intrínseca relação entre patrimônios naturais, precisamente os classificados como geológicos/geomorfológicos, e patrimônios classificados como culturais, tendo como ponto de partida o Cerro do Jarau e o Cerro dos Porongos, ambos situados no bioma Pampa, no sul do Brasil. Metodologicamente, buscou-se uma abordagem disruptiva em relação à predominante visão dualista entre ciências naturais e sociais. A pesquisa envolveu a sistematização de informações provenientes de outras pesquisas, leituras e avaliação de bibliografia, discussões acadêmicas e técnicas realizadas a partir dos órgãos ambiental e patrimonial, instrumentos legais e políticas de atuação destes. Neste contexto, a partir da caracterização dos valores destes sítios, a presente pesquisa analisa os cerros como patrimônios geomorfológicos e, ao mesmo tempo, culturais. Em comum, estes locais têm formas de grande beleza cênica e possuem importante referência histórica e identitária para a população gaúcha, sendo mencionados também como ícones na paisagem regional. Os morros testemunhos e cerros do Rio Grande do Sul ilustram objetivamente a artificialidade das divisões entre patrimônio natural e cultural, ainda necessitando ser efetivamente incorporados nas políticas públicas e no planejamento territorial, sendo necessária uma aproximação entre os órgãos ambientais e culturais em prol da efetiva proteção dos patrimônios conforme preconiza a legislação vigente.
\end{abstract}

Palavras-chave: Patrimônio Geomorfológico; Patrimônio Cultural; Geopatrimônio; Pampa; Cerro; Morro testemunho.

Abstract: This paper aims to discuss the intrinsic relationship between natural heritage, precisely those classified as geological/geomorphological, and heritage classified as cultural, starting from Cerro do Jarau and Cerro dos Porongos, both located in the Pampa biome, in the southern Brazil. Methodologically, a disruptive approach was sought in relation to the predominant dualistic view between natural and social sciences. The research involved the systematization of information from other researches, reading and evaluation of bibliographies, academic and technical discussions carried out from the environmental and patrimonial agencies, legal instruments and performance policies. In this context, from the characterization of the values of these sites, this research analyzes the buttes as geomorphological and cultural heritage. In common, these places have great scenic beauty forms and have an important historical and identity reference for the population of Rio Grande do Sul, also being mentioned as icons in the regional landscape. The buttes and large hills of Rio Grande do Sul objectively illustrate the artificiality of the divisions between natural and cultural heritage, still needing to be effectively incorporated into public policies and territorial planning, requiring an approximation between environmental and cultural agencies in order to effectively protect heritage according to the current 
legislation.

Keywords: Geomorphological Heritage; Cultural Heritage; Geoheritage; Pampa; Butte; Large hill.

\section{Introdução}

O bioma Pampa cobre uma superfície de $63 \%$ do território do Rio Grande do Sul (IBGE, 2004). Situado na porção sul do estado, este bioma estende-se também em território uruguaio e argentino (Overbeck et al., 2009). De acordo com a classificação dos domínios morfoclimáticos brasileiros proposta por Ab'Saber (1970) o bioma Pampa corresponde ao Domínio das Coxilhas Subtropicais com Pradarias Mistas, onde predomina vegetação campestre intercalada com formações arbóreas e arbustivas associadas aos cursos d'água.

Nos últimos anos, as áreas de campo nativo no Pampa têm sido convertidas, dando lugar ao cultivo de arroz e de soja. Pesquisas indicam que no período de 2000 a 2015 a área plantada com soja na porção gaúcha do bioma Pampa aumentou 188,5\% (Kuplich et al., 2018). Apesar da crescente pressão sobre o bioma, considerado a atual fronteira de expansão agrícola do estado, apenas $2,6 \%$ da sua área em território brasileiro é protegida por unidades de conservação, resultando no menor percentual nacional de proteção (Chomenko, Bencke, 2016; Fontana, Reed, 2019).

A carência de espaços especialmente protegidos contrapõe-se à biodiversidade e à geodiversidade existentes no Pampa, bem como à significativa quantidade de paisagens dotadas de relevância cultural e grande beleza cênica, como revela a pesquisa de doutorado de Vieira (2014). Do ponto de vista dos elementos mais marcantes da singularidade das formas de relevo presentes no Pampa, o presente artigo se propõe a destacar os cerros. O termo "cerro" corresponde a uma denominação regional utilizada para pequenas elevações ou colinas com vertentes acidentadas (Guerra, 1975).

Os cerros destacam-se em meio ao relevo regional caracterizado pela presença "(...) das colinas pluriconvexizadas, as quais a tradição convencionou chamar de coxilhas" (Ab'Saber, 2003, p. 22). Para além da singularidade do ponto de vista morfológico, muitos destes cerros são considerados locais de grande importância cultural, especialmente em um território historicamente envolvido em conflitos pela delimitação das fronteiras, constituindo pontos estratégicos para a vigilância e controle do território, local de esconderijo e, por vezes, palco de batalhas.

Neste contexto, o presente artigo objetiva discutir a intrínseca relação entre patrimônios classificados como naturais e os patrimônios classificados como culturais, tendo o Cerro do Jarau e o Cerro dos Porongos como exemplos. Ambos unem elementos de significativo valor geológico/geomorfológico associados à beleza cênica e, ao mesmo tempo, possuem forte valor referencial na cultura do povo gaúcho, sendo mencionados como ícones da paisagem do Pampa (Vieira, 2014). A partir dos exemplos, o presente artigo busca problematizar a questão da proteção patrimonial, 
tanto na esfera do sistema ambiental quanto cultural, apresentando o cenário atual, assim como contribuições e propostas para a discussão.

\section{Patrimônio geomorfológico e cultural}

O conceito de patrimônio geomorfológico, juntamente com o conceito de patrimônio geológico, vêm ganhando cada vez mais espaço na esfera de proteção do patrimônio mundial (Silva et al., 2020). O conceito de patrimônio geomorfológico surge com o intuito de abarcar a componente abiótica das paisagens, dentre as quais se destacam as formas de relevo e os processos responsáveis pela sua origem, quando estes apresentam significativo valor científico, pedagógico, cultural ou turístico (Brilha, 2005; Carcavilla et al., 2008).

Ao longo das últimas décadas este conceito vem se modificando, incorporando diferentes olhares especialmente no que se refere aos critérios de definição do patrimônio geológico (Castro et al., 2018). É exemplo o trabalho de Brilha (2016), que mais recentemente passa a considerar o valor científico como preponderante para a definição do mesmo. Apesar de ainda não haver consenso, fica evidente que se trata de um conceito em permanente construção e que a necessária interface social tem mostrado a importância da aproximação com a abordagem cultural (Castro et al., 2018; Reynard, Giusti, 2018; Silva et al., 2020).

Neste sentido, o conceito de patrimônio geomorfológico remete ao componente natural que está associado a paisagens de elevado valor estético, sendo considerados atrativos visuais que chamam a atenção do observador (Coratza, Hobléa, 2018). Tratam-se de locais que são selecionados como relevantes para serem conservados e repassados às gerações futuras em função do reconhecimento dado pela sociedade atual (Reynard, Giusti, 2018). Neste sentido, os locais de interesse geomorfológico possuem elementos que justificam sua valoração pelos indivíduos ou coletividades, os quais refletem olhares, percepções e interesses expressos na intenção de preservá-los para a posteridade.

A partir do exposto e, considerando que a atribuição de valor por parte da sociedade é inerente ao reconhecimento de um bem/elemento/espaço enquanto patrimônio (Castro et al., 2018), é possível afirmar que o que aproxima o conceito de patrimônio geomorfológico da abordagem cultural é a percepção do seu caráter de herança.

No caso dos patrimônios classificados como geomorfológicos, tais valores são definidos pela sociedade e sua cultura, estando ancorados em elementos abióticos, geológicos e geomorfológicos, expressos na paisagem, conforme exposto por Pereira e Martins (2018, p. 1167):

Se as características específicas de uma forma de relevo, o seu processo de formação e a sua morfodinâmica são fatores primordiais para a avaliação do seu interesse científico no domínio das geociências, o reconhecimento do seu valor patrimonial depende de um contexto histórico e sociocultural específico. 
Neste sentido, Pereira et al. (2008) afirmam que os locais de relevante valor geomorfológico passam a ser abordados com caráter patrimonial por meio do DecretoLei $n^{\circ} 25$, de 30 de novembro de 1937 (Brasil, 1937). Estabelecendo a "protecção de monumentos naturais, bem como os sítios e paisagens que importe conservar e proteger pela feição notável (...)" (Brasil, 1937), este marco legal também inova ao classificar os locais sujeitos a tal tombamento como bens inalienáveis.

$\mathrm{Na}$ década de 1970 as discussões a nível internacional avançam por meio da Convenção para a Proteção do Patrimônio Mundial, Cultural e Natural (Castro et al., 2018; Silva et al., 2020). A nível nacional, meio século depois do Decreto-Lei no 25 de 30 de novembro de 1937 tem-se a promulgação da Constituição Federal Brasileira (Brasil, 1988). Neste documento a perspectiva da preservação do patrimônio geomorfológico é novamente abordada, mais uma vez de maneira associada ao componente cultural:

Art. 216. Constituem patrimônio cultural brasileiro os bens de natureza material e imaterial, tomados individualmente ou em conjunto, portadores de referência à identidade, à ação, à memória dos diferentes grupos formadores da sociedade brasileira, nos quais se incluem: (...) V - os conjuntos urbanos e sítios de valor histórico, paisagístico, artístico, arqueológico, paleontológico, ecológico e científico. (Brasil, 1988)

Ainda na esfera legal, outro importante marco para a efetivação da proteção do patrimônio geomorfológico foi a instituição do Sistema Nacional de Unidades de Conservação - SNUC (Pereira et al., 2008). Apesar de uma abordagem predominantemente biológica, a Lei 9.985/2000 contempla elementos que permitem a proteção do patrimônio geológico e geomorfológico. No Art. $4^{\circ}$, que trata dos objetivos, constam, respectivamente, os incisos VI e VII: "proteger paisagens naturais e pouco alteradas de notável beleza cênica" e "proteger as características relevantes de natureza geológica, geomorfológica, espeleológica, arqueológica, paleontológica e cultural" (Brasil, 2000).

Pereira et al. (2008) e Couto e Figueiredo (2019) consideram que o SNUC apresenta tipologias de proteção dentre as quais o patrimônio geológico/geomorfológico tem destaque. O principal exemplo é a tipologia de Monumento Natural, que tem por objetivo "preservar sítios naturais raros, singulares e/ou de grande beleza cênica" (Brasil, 2000). Ainda que predominem categorias de proteção voltadas a assegurar a preservação com enfoque na biodiversidade, o SNUC constitui um dos principais mecanismos atualmente existentes para a efetivação da proteção do patrimônio geomorfológico em território nacional.

Por outro lado, importa também considerar os mecanismos de proteção do patrimônio cultural nacional. O conceito de patrimônio é culturalmente construído e, por isto, apresenta grande complexidade, podendo variar em função do tempo, das percepções e vivências experienciadas pelos indivíduos (Coratza, Hobléa, 2018; Castro et al., 2018). Dessa forma, seus instrumentos de proteção também sofrem modificações ao longo do tempo. Duas décadas após a Constituição, surge a 
Chancela da Paisagem Cultural, sendo esta definida como: "uma porção peculiar do território nacional, representativa do processo de interação do homem com o meio natural, à qual a vida e a ciência humana imprimiram marcas ou atribuíram valores" (IPHAN, 2009).

Esta definição também permite abarcar elementos de relevante interesse geológico e geomorfológico associados a valores intrínsecos das paisagens. As características geomorfológicas singulares também são elementos importantes em toda paisagem cultural, permitindo reforçar a perspectiva da interelação entre os conceitos de patrimônio geomorfológico e de patrimônio cultural. Na mesma linha da valoração das paisagens como patrimônio da coletividade, o geógrafo Aziz Ab'Saber (2003) na obra "Os domínios de natureza no Brasil: potencialidades paisagísticas" ressalta que os espaços vividos pelas comunidades são territórios herdados, porém mais que territórios, as comunidades herdaram paisagens morfoclimáticas, biogeográficas e ecológicas:

Mais do que simples espaços territoriais, os povos herdaram paisagens
e ecologias, pelas quais certamente são responsáveis, ou deveriam ser
responsáveis. Desde os mais altos escalões do governo e da
administração até o mais simples cidadão, todos têm uma parcela de
responsabilidade permanente, no sentido da utilização não-predatória
dessa herança única. (Ab'Saber, 2003, p. 10)

Nesta perspectiva, a noção de patrimônio se amplia, buscando superar a visão segmentada e artificial, ainda comum, que divide os patrimônios, conforme seus componentes, em naturais e culturais (Coratza, Hobléa, 2018). Ainda a respeito da abordagem fragmentada envolvendo a discussão do patrimônio natural e cultural, Pereira e Martins (2018, p. 1167) afirmam que "a artificialidade desta divisão é particularmente evidente nos conceitos de paisagem geomorfológica e de paisagem cultural, uma vez que a segunda é indissociável da primeira".

Reynard e Giusti (2018) consideram que o patrimônio geológico e o patrimônio cultural são integrados, citando vários exemplos de como o primeiro pode influenciar no segundo, assim como outros casos em que a cultura de determinado grupo social traz influência na percepção do patrimônio geológico. Da mesma forma, Castro et al. (2018, p. 387) apontam a necessidade de uma perspectiva integral na abordagem do assunto: "(...) talvez o caminho a ser trilhado envolva a percepção do patrimônio em seu sentido integral. Sem o recorte cartesiano que nos trouxe ao momento de separar e dividir as coisas em categorias, adjetivando-as."

Neste sentido, as pesquisas têm se encaminhado para a aplicação do conceito de patrimônio geomorfológico de modo mais amplo e interelacional, considerando-o por meio de uma abordagem holística (Coratza, Hobléa, 2018), onde se torna impossível dissociar patrimônio geomorfológico de patrimônio cultural (Pereira, Martins, 2018). Um exemplo neste sentido se expressa na simbiose entre patrimônio ambiental e cultural, que se dá por meio do conceito de paisagens culturais da UNESCO (Reynard, Giusti, 2018). 
Como exemplos ilustrativos de lugares em que às características geomorfológicas se unem às características histórico-culturais únicas na sua valoração do ponto de vista patrimonial podem ser citados: a) Cidade do Rio de Janeiro, reconhecida pela UNESCO em 2009 como Paisagem Cultural, tendo como título da sua candidatura "Rio de Janeiro: Paisagens Cariocas entre a Montanha e o Mar" (Ribeiro, 2016; Silva et al., 2020); b) O conjunto arquitetônico e paisagístico de Lençóis, na Bahia, tombado pelo Instituto do Patrimônio Histórico e Artístico Nacional - IPHAN no ano de 1973, no qual a geomorfologia está fortemente presente, como sugerem as descrições sobre a característica e valoração do bem tombado:

\begin{abstract}
A cidade situa-se na região centro-oeste da Bahia, em um anfiteatro natural na encosta oriental da Serra do Sincorá. O conjunto é bastante rico e interessante, tendo conservado muito das suas características originais, além de estar situado em uma região de serras, na área do Parque Nacional da Chapada Diamantina, famosa por uma deslumbrante beleza natural. (IPHAN, 2020a)
\end{abstract}

\title{
1.1. Pampa: patrimônios múltiplos
}

O Pampa, embora ainda não reconhecido como tal, constitui exemplo claro de como as características geomorfológicas se unem às características culturais na formação de valor do ponto de vista patrimonial. Há significativos elementos na paisagem do Pampa que sugerem a valoração das formas de relevo, conforme destacado no fragmento a seguir, de autoria de um dos mais importantes geógrafos brasileiros:

Trata-se, talvez, da mais bela área de colinas do território brasileiro. A Campanha é uma espécie de 'país' de horizontes distendidos e desdobrados, a perder de vista na direção das fronteiras 'castelhanas' do Uruguai e da Argentina. (Ab'Saber, 2003, p. 22)

$O$ autor destaca ainda os cerros como formas de relevo que "quebram a monotonia das paisagens que se repetem" (Ab'Saber, 2003, p. 22). Constituindo feições ruiniformes de destacado valor paisagístico, os cerros correspondem a elevações que se destacam na paisagem geralmente mantidas por uma litologia mais resistente. Neste sentido, constituem morros testemunhos que ilustram processos de evolução das paisagens, assumindo um importante papel educativo em função do seu caráter didático. Os cerros são elementos de destaque, pontos focais, especialmente quando se encontram isolados em meio a amplidão da paisagem predominantemente plana do Pampa, conforme ilustrado na Figura 1.

Estes locais apresentam valores intrínsecos em função da existência das formas de relevo desenvolvidas a partir de fenômenos geológicos e da dinâmica superficial atuante. Do ponto de vista dos elementos mais marcantes na paisagem do Pampa, a pesquisa de Vieira (2014) destaca estas formas de relevo em razão da significativa relevância cultural e grande beleza cênica:

Todos os cerros foram citados por vários pesquisadores como "monumentos naturais que se destacam na paisagem", pela "morfologia imponente e composição ecológica", pela "importância histórica e identitária com a comunidade local", "para preservar a 
possibilidade de se ver ao longe", e pela "sua formação geológica, geomorfológica e a vegetação. (Vieira, 2014, p. 191-192)

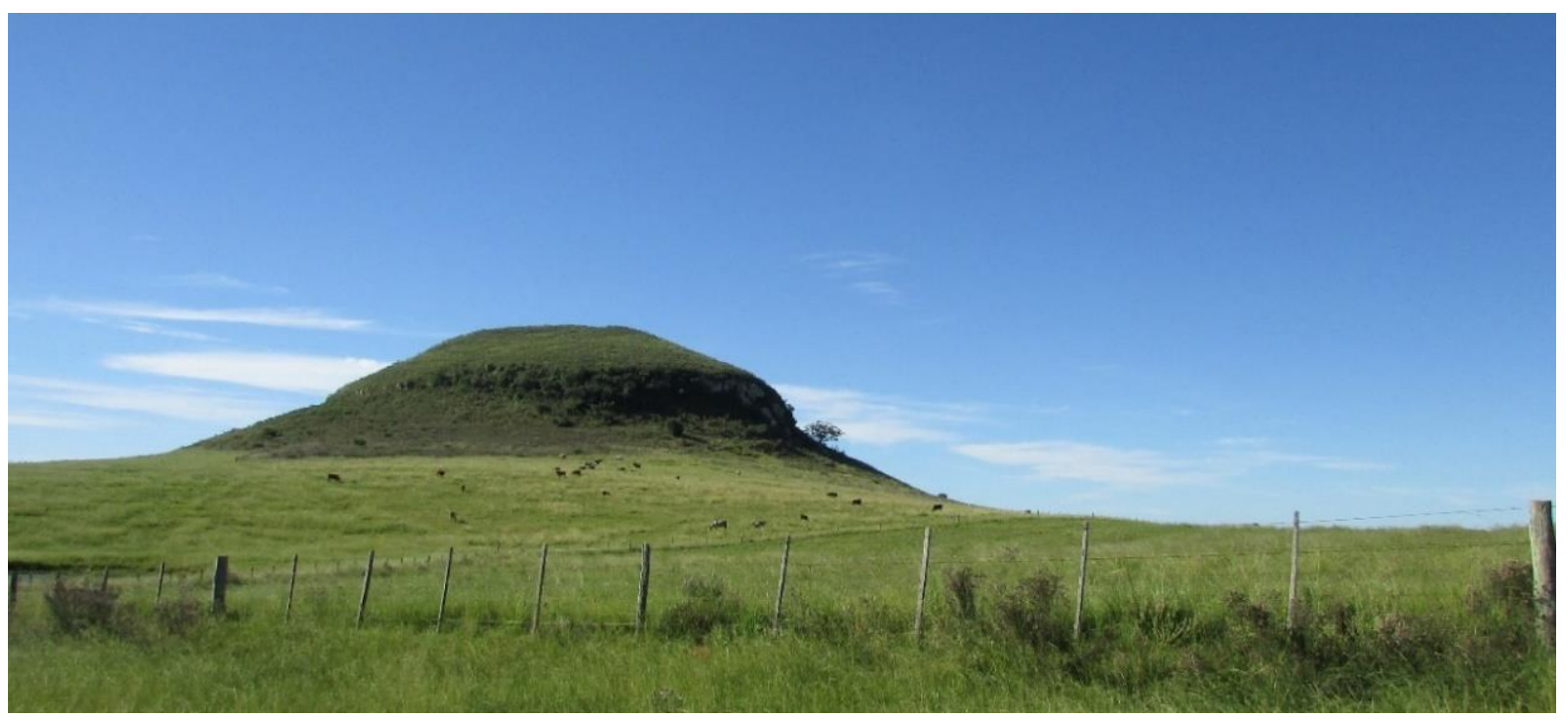

Figura 1: Paisagem do Pampa com destaque para o morro testemunho isolado.

O Pampa e seu relevo ainda estão fortemente marcados em manifestações culturais regionais, como seja: na música produzida no estado do Rio Grande do Sul; na literatura, sendo o local onde se passam romances e onde se originam contos e lendas; na história, tendo sido palco de batalhas relacionadas com a Guerra Farroupilha (1835 - 1845), a Revolução Federalista (1893 - 1895) e a Revolução de 1923; nos saberes, expressões e celebrações cotidianas relacionadas à atividade pecuária, a qual é fortemente ligada ao bioma, tendo influência na origem de uma diversidade de elementos da cultura gaúcha, a exemplo das lidas campeiras (Wiggers, 2015).

Uma complexa gama de elementos formados numa intrínseca relação entre os diversos grupos e etnias e o Pampa, legaram ao bioma paisagens repletas de códigos e significados de valor cultural. Alguns dos elementos que estão registrados nesta paisagem e permanecem presentes no imaginário da população são os currais e muros de pedra (Figura 2), os sítios arqueológicos e antigos marcos fronteiriços. Além destes, cabe ainda mencionar as charqueadas, que correspondem a propriedades rurais que, no final do século XVIII e início do século XX, produziam carne salgada e dessecada (charque) a partir do gado proveniente do Pampa gaúcho (Pesavento, 1982). 


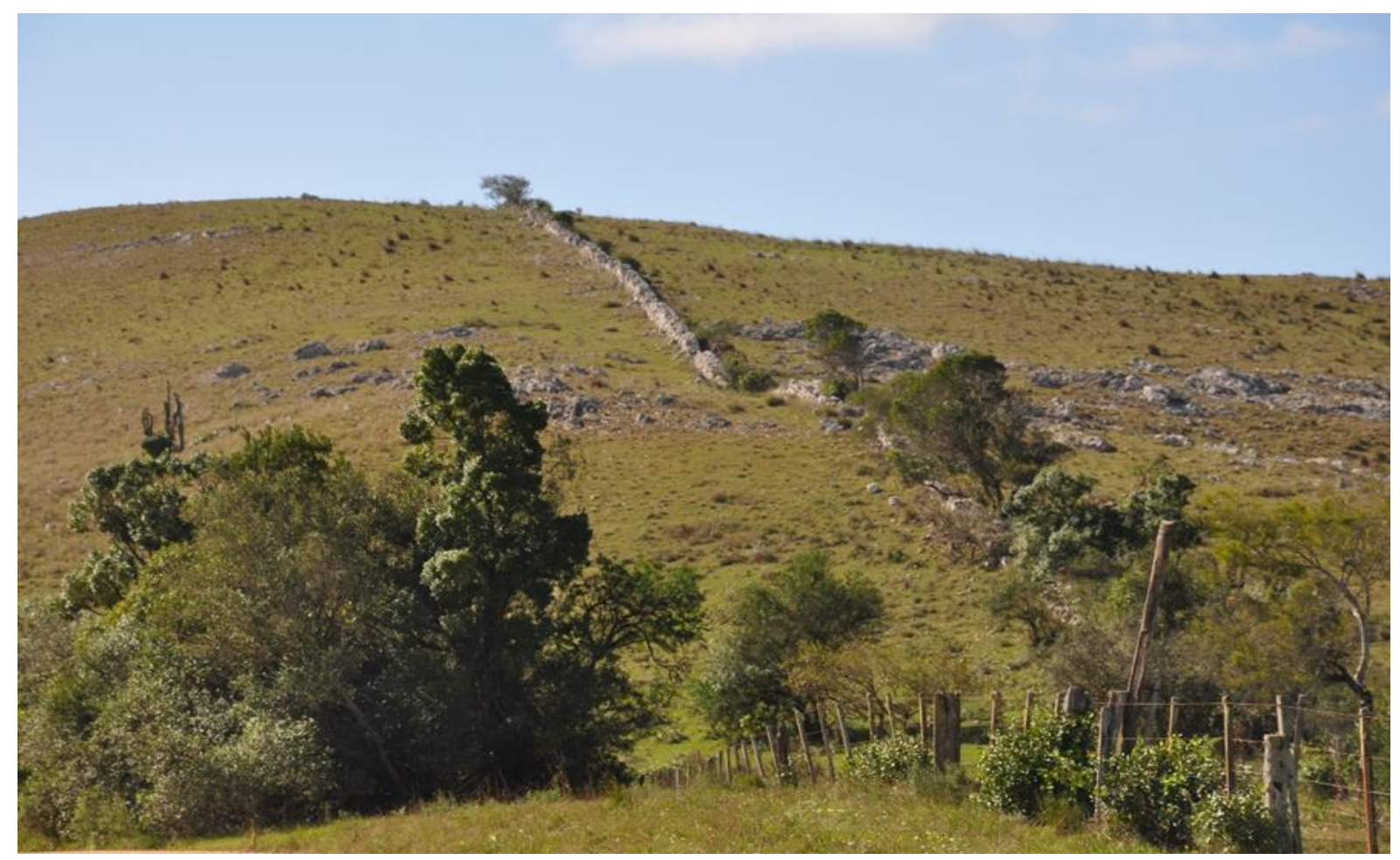

Figura 2: Muro de pedra característico do Pampa.

\section{Metodologia}

O presente trabalho adotou uma abordagem crítica na busca de uma aproximação entre as ciências sociais e naturais na caracterização dos valores atribuídos aos dois sítios escolhidos como exemplo para ilustrar a discussão proposta neste artigo, sendo orientado, desde o seu início, pela colocação de Suertegaray (2018), na qual a autora aponta que a temática ambiental remete a uma abordagem metodológica integrada, o que ainda é algo desafiador diante da tradicional divisão das ciências em naturais e sociais.

A escolha pelos locais de estudo, o Cerro do Jarau e o Cerro dos Porongos, deveuse ao fato de que ambos despertaram significativo interesse científico nas últimas décadas, sendo estudados por pesquisadores das mais diversas áreas das ciências naturais e sociais (Delphim, 2009; Crósta et al., 2010; Salaini, Graeff, 2011; Alves, 2012; Sánchez, Garcia, 2013; Sánchez et al., 2014; Bilhar et al., 2019). Além disso, são considerados paisagens de máxima valoração no estudo relativo à beleza cênica da paisagem do bioma Pampa (Vieira, 2014). Portanto, estes sítios foram considerados excelentes exemplos para discussão da interdependência dos valores naturais e culturais, quando dos processos de patrimonialização de bens e lugares.

Considerados estes elementos, a análise envolveu a leitura e sistematização de informações provenientes de pesquisas e trabalhos acadêmicos, artigos e bibliografia diversa, pareceres técnicos de órgãos ambientais e culturais de diferentes esferas de atuação, e os instrumentos legais de proteção propostos para os dois sítios. Neste contexto, as áreas de estudo foram localizadas no Mapa de Áreas Prioritárias para Conservação, elaborado pelo Ministério do Meio Ambiente (MMA, 2007). De posse destas informações foram realizadas saídas de campo visando qualificar as análises. 
Diante do exposto, foi realizada a caracterização dos valores destes sítios, apontando os cerros como patrimônios geomorfológicos e, ao mesmo tempo, culturais, privilegiando as inter-relações entre estes elementos. Na sequência, a sistematização das informações resultou na elaboração de um quadro comparativo que permite evidenciar valores de cada sítio, trazendo elementos tanto da geomorfologia, quanto do ponto de vista histórico, de memória e identidade. Tal procedimento também favoreceu o estabelecimento de comparações evidenciando similaridades de condições quanto à situação atual de conservação.

\section{Resultados e discussões}

No que se refere à importância ambiental, as áreas de estudo estão situadas em locais de interesse para a conservação, conforme indicado no Mapa de Áreas Prioritárias para Conservação (MMA, 2007). O referido estudo enfatiza a importância biológica, sendo utilizado para indicar locais para ações prioritárias visando a conservação. Neste contexto, o Cerro do Jarau está situado em área considerada de prioridade "Extremamente Alta" e importância "Muito Alta", enquanto o Cerro dos Porongos está inserido em área de prioridade e importância "Extremamente Alta", conforme ilustrado no mapa da Figura 3.

\section{LOCALIZAÇÃO DO CERRO DO JARAU E DO CERRO DOS PORONGOS EM RELAÇÃO AO BIOMA PAMPA E SUAS ÁREAS PRIORITÁRIAS PARA A CONSERVAÇÃO NO RIO GRANDE DO SUL}

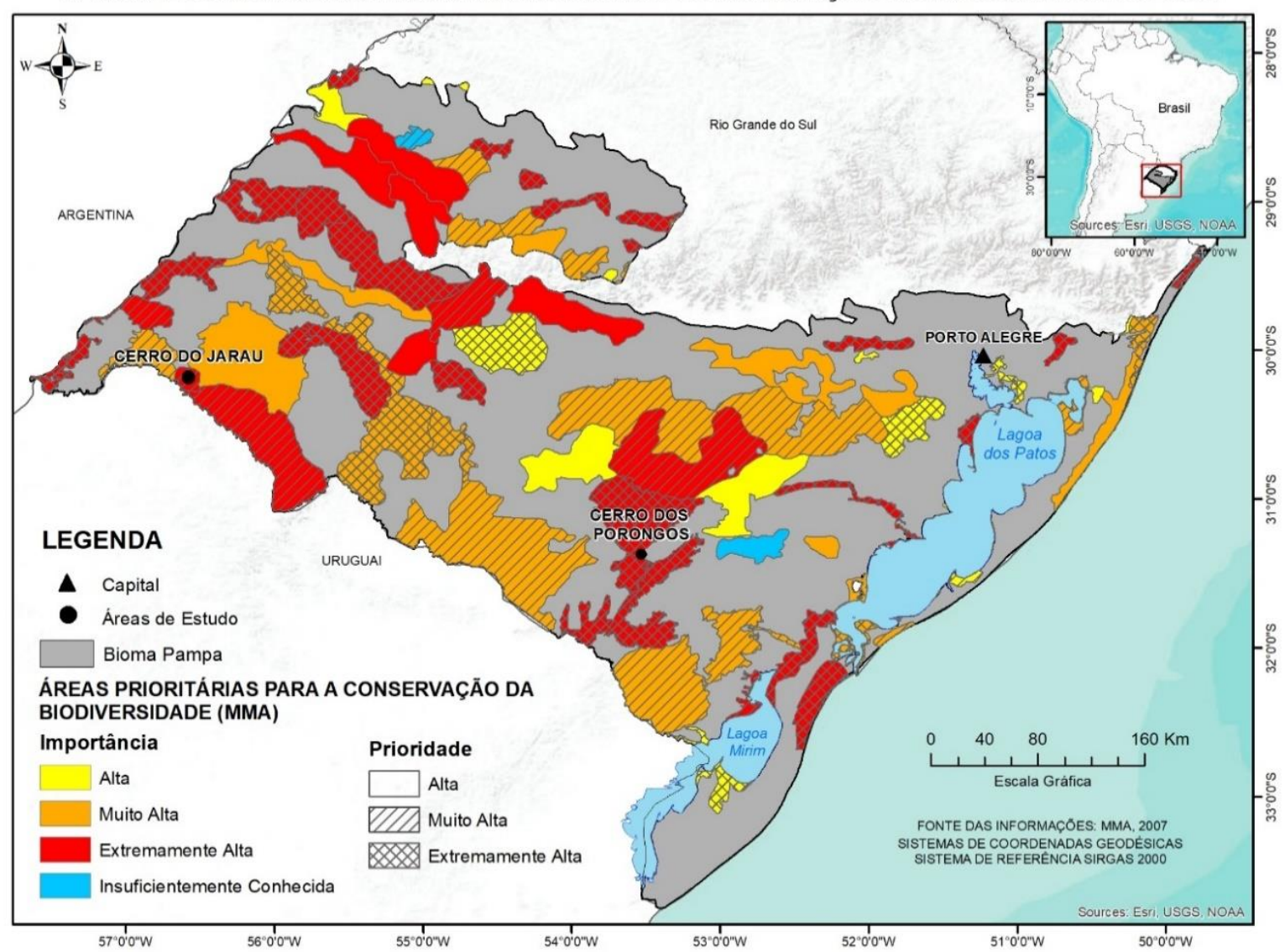

Figura 3: Localização das áreas de estudo em relação às áreas prioritárias para a conservação da biodiversidade no bioma Pampa.

Fonte: Elaborado pelas autoras. 


\subsection{Cerro do Jarau}

Situado no município de Quaraí, sudoeste do estado do Rio Grande do Sul, fronteira entre Brasil e Uruguai, o Cerro do Jarau exemplifica a condição de paisagem de exceção, ícone regional (Figura 4). Constituído por um conjunto de elevações que pode ser visualizado a longa distância, trata-se de uma das principais formas de relevo de destaque em meio aos campos em relevo plano a suavemente ondulado resultado de dissecação homogênea em homoclinal dissimétrica do Planalto Meridional (Ab'Sáber, 1970).

A singularidade desta paisagem está relacionada com os aspectos geológicos e geomorfológicos que explicam a morfogênese das formas. Crósta et al. (2010) apontam que a gênese do Cerro do Jarau está associada ao impacto de um meteorito (astroblema), resultando numa cadeia de morros em formato semicircular, com elevação que passa dos $150 \mathrm{~m}$ em relação às áreas do entorno. O impacto é responsável pela complexidade litológica que resulta na exposição de litologias areníticas em uma região onde predominam as rochas vulcânicas, além da presença de material vitrificado, indicativo do impacto (Crósta et al., 2010; Sánchez et al., 2014).

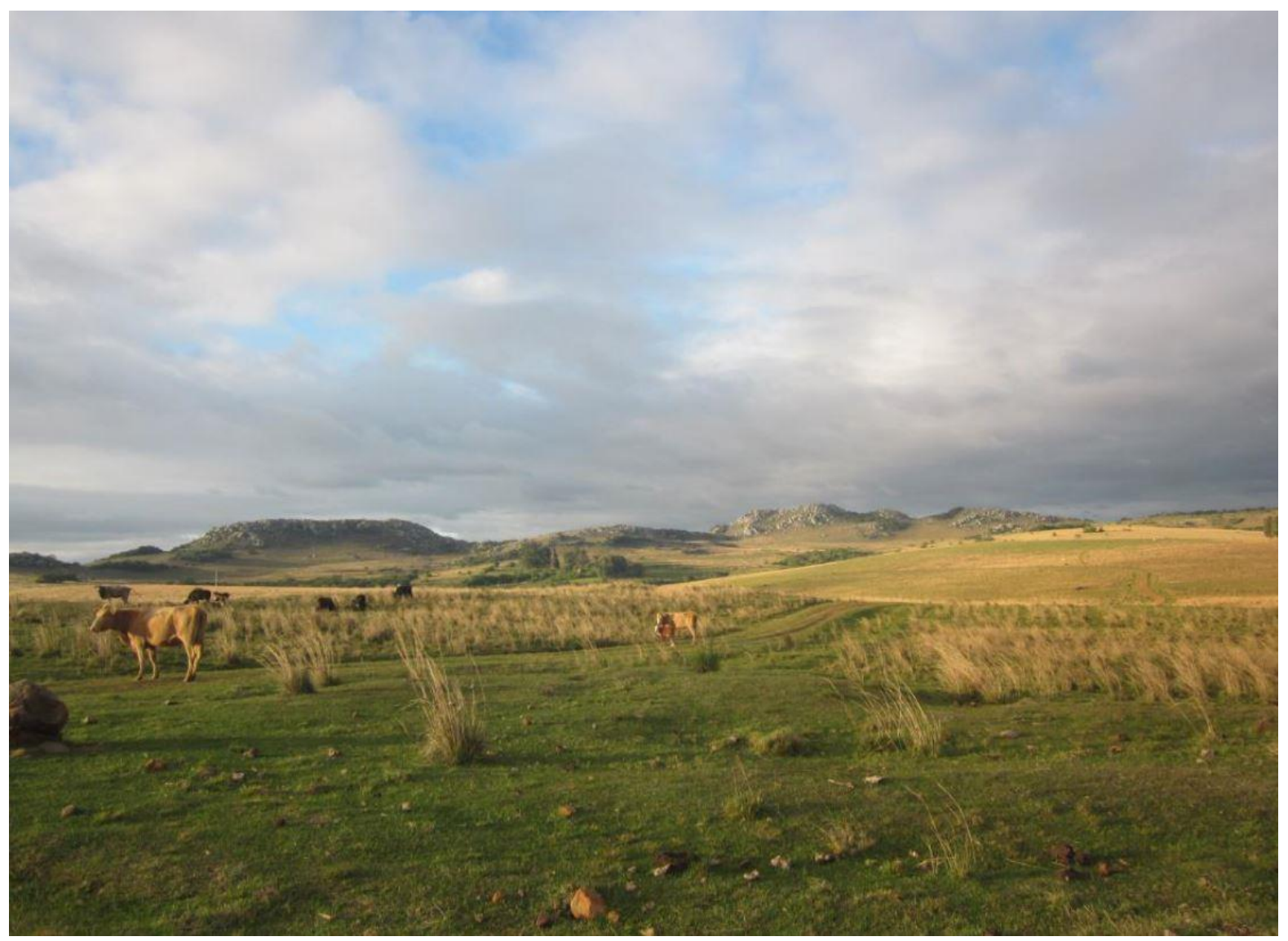

Figura 4: Vista do conjunto de morros que compõem a paisagem do Cerro do Jarau.

Fonte: SEMA (2013). 
Por se destacar em relação às áreas do entorno, os elementos morfológicos fazem com que o local seja considerado paisagem de máxima valoração e ícone de referência paisagística para a população gaúcha, por ser palco de uma das mais famosas lendas sul-rio-grandenses, recolhida e transcrita da tradição oral para a literatura por Simões Lopes Neto em "Salamanca do Jarau" (SEMA, 2013). É o que indica a pesquisa de Vieira (2014), que aponta a paisagem do Cerro do Jarau como sendo lembrada por indivíduos e coletivos em função da identificação e do sentido de pertencimento, fato que associa o local ao contexto histórico e cultural, sendo um dos principais cerros de importância para o folclore gaúcho.

Em síntese, o Cerro do Jarau é dotado de significativa relevância cultural sendo esta associada a valores históricos, geológicos, geomorfológicos, ecológicos e paisagísticos, constituindo local de interesse científico e turístico, por se tratar de um dos 8 (oito) locais que registram feições geológicas e geomorfológicas associadas ao impacto de meteoritos no país e único no estado do Rio Grande do Sul (Melo, 2020). Seu caráter de singularidade promove uma beleza cênica que exerce atração visual no espectador, justificando a adoção de medidas de proteção (SEMA, 2013).

A associação de valores, por sua vez, reflete-se também na significativa relevância ecológica, o que explica a atribuição de prioridade extremamente alta para a conservação sob o ponto de vista biológico, conforme ilustrado na Figura 3. A complexidade geológica/geomorfológica resulta em uma diversidade de ambientes que, por sua vez, se traduz no significativo aumento da biodiversidade local, indicada pela ocorrência de 64 espécies vegetais endêmicas, raras e/ou ameaçadas, conforme apontado no trabalho de Alves (2012).

A biodiversidade, portanto, tem estreita relação com a geodiversidade do Cerro do Jarau. Assim, trata-se de um local de evidente interesse tanto para a geoconservação quanto para a preservação da biodiversidade. Cabe ainda mencionar que, por se tratar do ponto mais elevado da região, o Cerro do Jarau foi utilizado como local estratégico nas batalhas pela demarcação das fronteiras coloniais entre Portugal e Espanha. Todos estes elementos fazem com que, na atualidade, o local venha sendo objeto de pesquisas científicas das mais diversas áreas do conhecimento, além de ser considerada uma paisagem de referência para a população gaúcha em função do seu valor simbólico, identitário e cultural.

\subsection{Cerro dos Porongos}

Geologicamente o Cerro dos Porongos é formado por rochas metassedimentares com intercalações de camadas de micaxistos e quartzitos puros leitosos extremamente fraturados (Bilhar et al., 2019). Situado no escudo cristalino, o local apresenta relevo ondulado onde predominam coxilhas intercaladas com afloramentos rochosos geralmente situados nas cristas dos cerros (Figura 5). O relevo apresenta aspecto movimentado, com morros alinhados e topos ondulados em formato característico de intemperismo de rochas cristalinas em ambiente tropical (Ab'Sáber, 1970). No local as formas de relevo lembram o formato de porongos, frutos que são secos e trabalhados 
artesanalmente para serem utilizados como recipiente para o preparo da bebida mais tradicional do povo gaúcho, o chimarrão.

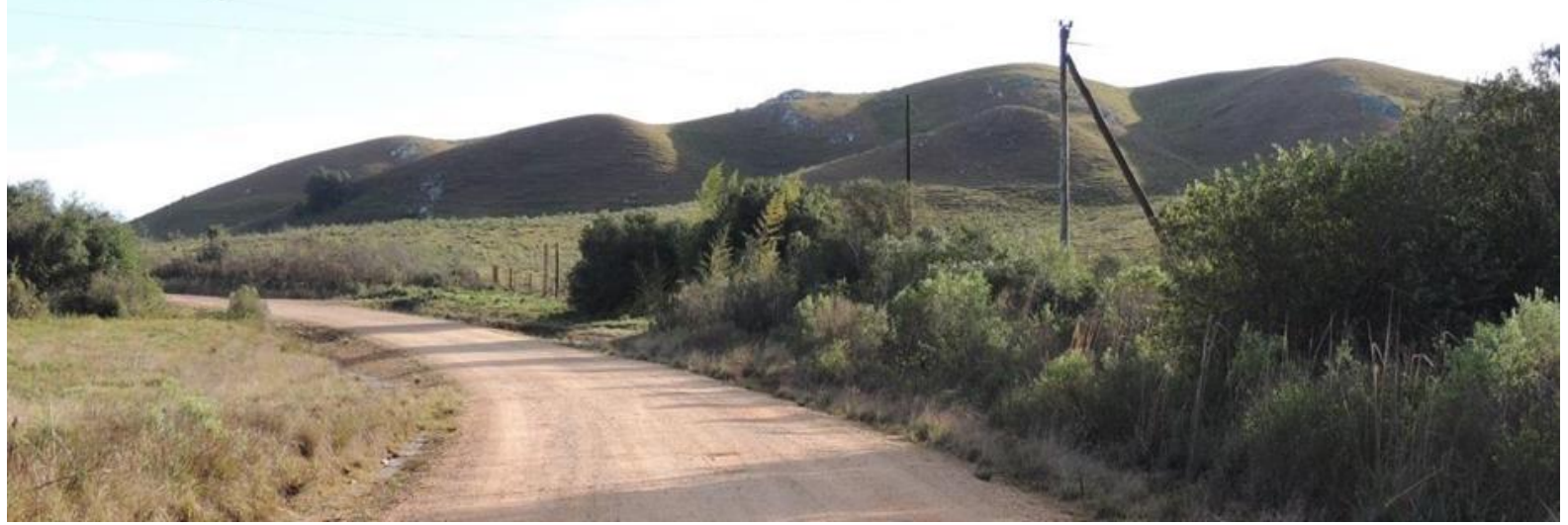

Figura 5: Vista das formas de relevo que compõem o Cerro dos Porongos.

Localizado no município de Pinheiro Machado, o Cerro dos Porongos foi palco de importante episódio na história do Estado. Na noite de 14 de novembro de 1844, as forças do Império surpreenderam o acampamento da tropa de Lanceiros Negros, pertencentes ao exército Farroupilha. Surpreendidos e desarmados, os soldados negros foram massacrados. Há evidências de que o ataque das tropas do Império foi decorrente da traição do líder Farroupilha David Canabarro, que estava disposto a aceitar o acordo de paz proposto, restando pendente apenas a prometida liberdade aos escravos (Salaini, Graeff, 2011).

Para além das controvérsias existentes quanto à ocorrência de uma traição, o que é consenso é que o Cerro dos Porongos se constitui em um importante local para a história do Rio Grande do Sul. A valoração simbólica está materializada na paisagem, por meio de dois marcos que homenageiam os mortos da Batalha dos Porongos (Figura 6), batalha derradeira que culminou no final da Revolução Farroupilha (18351845). Situados em vertentes opostas desta elevação, os dois marcos foram construídos com 3 (três) décadas de diferença, o que reitera a manutenção da importância do local ao longo do tempo, devendo ser preservado para as futuras gerações.

Diante da valoração atribuída ao local, Salaini e Graeff (2011) afirmam que o Cerro dos Porongos cumpre papel de lugar de memória, o que é corroborado pelo parecer de Delphim (2009, p. 27):

Porongos é o símbolo mítico de uma das mais elevadas aspirações humanas, a liberdade. Ainda que de forma frustrada, isso deve ser enfatizado por qualquer proposta de uso, agenciamento ou preservação do sítio. 


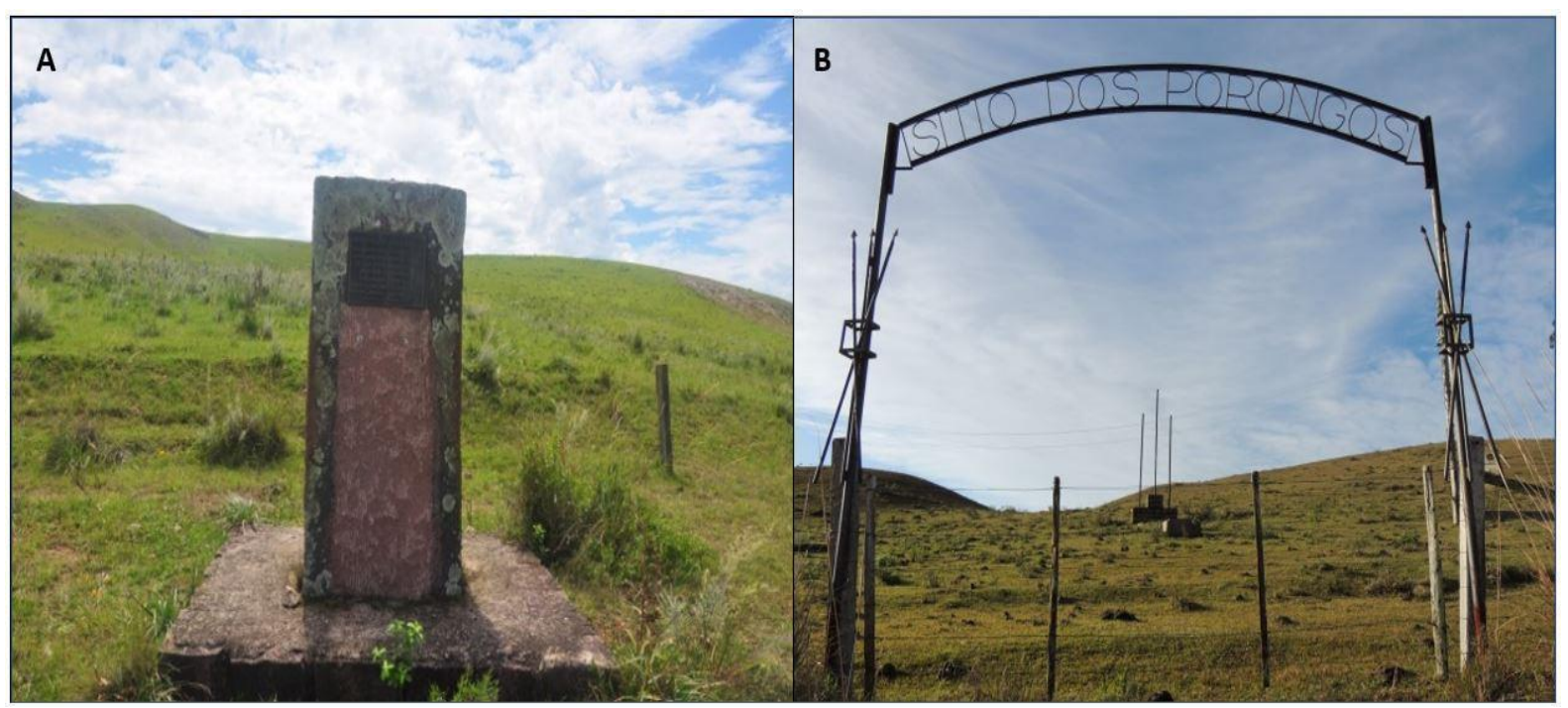

Figura 6: Marcos situados na base do Cerro dos Porongos. Fotografia A - marco datado de 1983 e Fotografia B marco datado de 2013.

Neste sentido, pesquisadores apontam que o Cerro dos Porongos deve integrar o roteiro de reconstrução identitária de grupos negros no sul do Brasil (Delfhim, 2009). Ressalta-se o valor étnico do local para a população negra, o que é indicado por meio da realização de celebrações culturais neste local, sendo atribuída importância para a manutenção da memória deste grupo social, a fim de permitir a elaboração (e até mesmo a reelaboração) de seu significado simbólico para a formação da identidade e cultura da sociedade gaúcha como um todo (Salaini, Graeff, 2011).

Ancorado nas formas de relevo e nos campos que permitem o olhar ao horizonte, o Cerro dos Porongos se configura em uma paisagem de valor simbólico representativo do Pampa. Atuando como elemento essencial desta valoração, o relevo é o elemento central do ponto de vista cênico:

\begin{abstract}
Sob o ponto de vista paisagístico, o monumento mais eloqüente para exprimir os fatos históricos que aí ocorreram é a própria paisagem. Nenhuma inserção arquitetônica na paisagem poderia exprimir com maior propriedade o valor e a significação do sítio. A simplicidade do quadro cênico onde ocorreu a batalha deveria ser preservada sem intervenções sofisticadas(...). A importância do sítio histórico é indestacável da condição de paisagem cultural. (Delfhim, 2009, p. 24)
\end{abstract}

Outra marca na paisagem regional são os cemitérios familiares posicionados estrategicamente no alto das coxilhas (Figuras 7 e 8), além das taipas e/ou mangueiras de pedra (conforme já ilustrado na Figura 2). Os primeiros são antigos e imponentes túmulos que permitiam distinguir socialmente seus proprietários, constituindo elemento indicativo da elevada hierarquia social. Além deste aspecto, constituem elemento marcantes na paisagem e muito representativos da identidade cultural desta região, conforme descrito no trecho a seguir:

É comum no Pampa, sobre cerros e coxilhas, o túmulo isolado. Expressão do desejo de seus moradores de serem enterrados em lugares altos, no domínio de suas terras. Trata-se de um símbolo de 
identidade com a terra e com a lida do campo. (Chomenko, Bencke, 2016, p. 40)

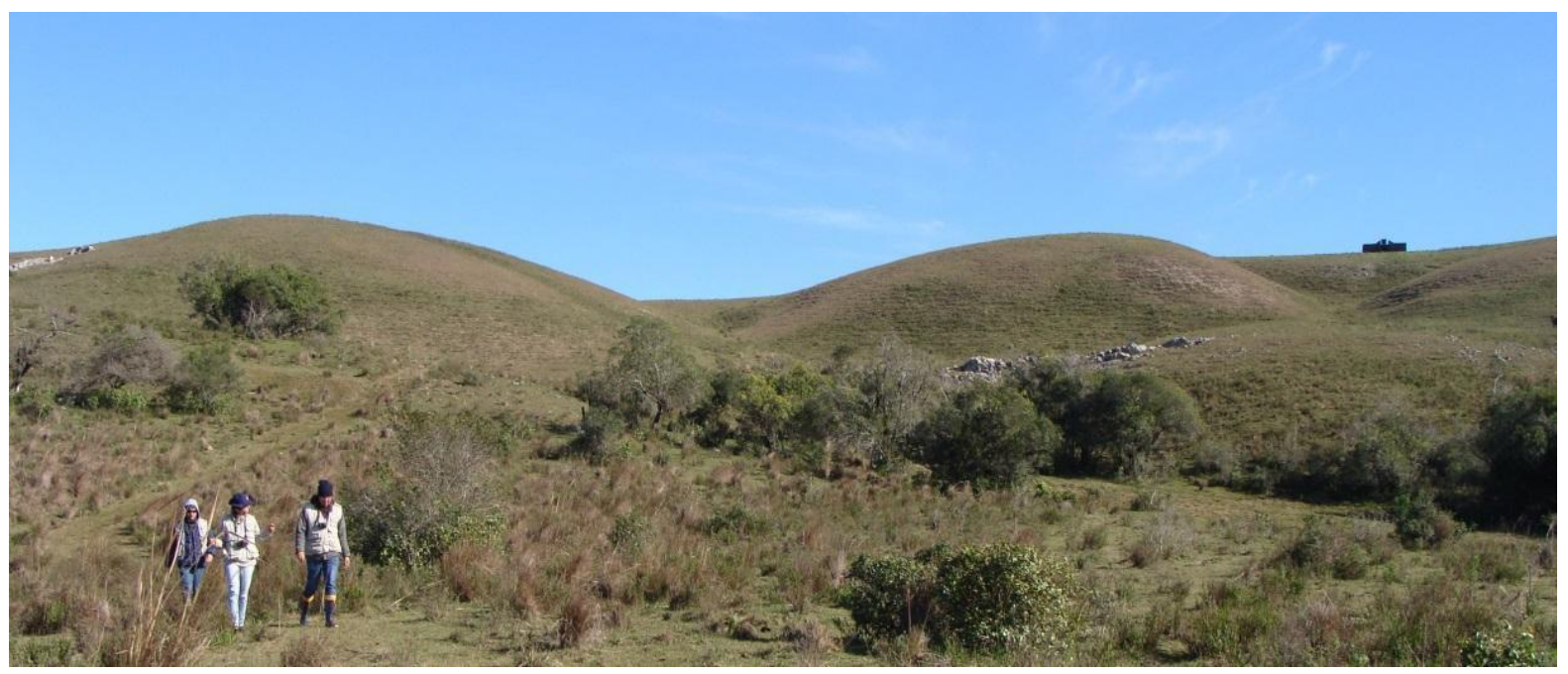

Figura 7: No topo da coxilha à direita, túmulo familiar típico do Pampa.

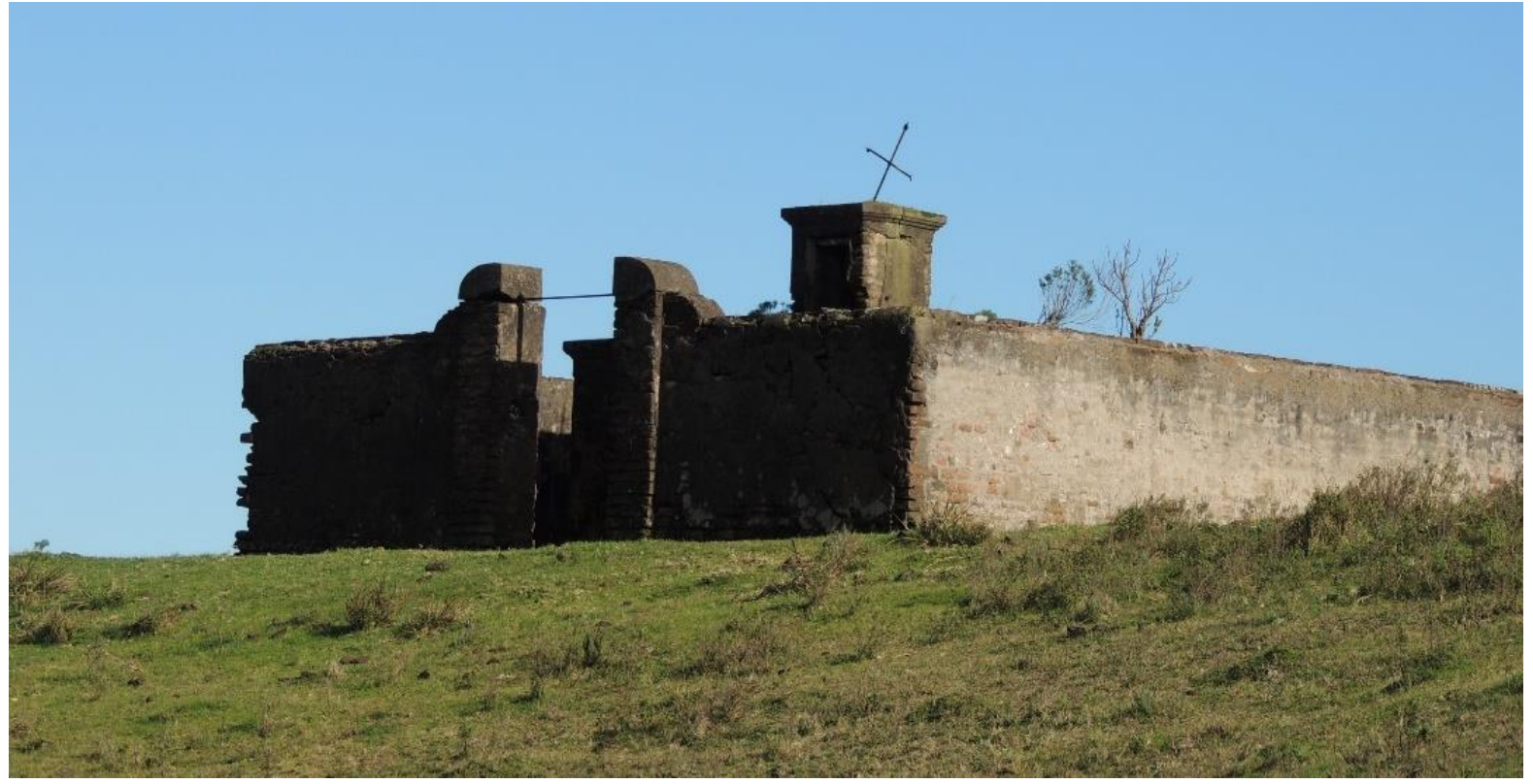

Figura 8: Detalhe do túmulo familiar centenário na localidade do Cerro dos Porongos.

Neste contexto, o Cerro dos Porongos possui componentes naturais representativos do Pampa, além de valor cultural simbólico associado ao contexto histórico e étnico, tornando-se um lugar representativo da intrínseca relação entre o relevo e as práticas culturais que se estabelecem, as quais imprimem marcas ou valores relativos à identidade e memória de diferentes grupos formadores da sociedade. Desta forma, o Cerro dos Porongos carrega fortes componentes sociais, valores culturais, materiais e imateriais, que permitem considerar o local um patrimônio cultural, conforme disposto na Constituição Federal (Brasil, 1988). 


\subsection{Situação atual das políticas públicas de proteção}

Tendo por base o exposto a respeito dos valores intrínsecos ao Cerro do Jarau e ao Cerros do Porongos, cabe uma breve discussão a respeito das medidas visando proteger os valores atrelados a estes sítios. Apesar de ambos possuírem estudos indicando a necessidade de conservação, atualmente nenhum deles está protegido, seja no âmbito do sistema ambiental, seja por políticas de proteção na esfera cultural.

Conforme mencionado no item de fundamentação teórica, apesar da prerrogativa legal existente, atualmente não constam ações que efetivamente incidam sobre amplas paisagens do Pampa considerando valores ancorados nas formas de relevo, conforme constatado por meio de pesquisa na lista de bens tutelados, tombados ou registrados, tanto em âmbito federal, pelo IPHAN, quanto em âmbito estadual, pelo Instituto do Patrimônio Histórico e Artístico do Estado - IPHAE.

No caso do Cerro do Jarau constam estudos iniciais para a criação de unidade de conservação junto ao órgão estadual (SEMA, 2013). O documento indica a categoria de Monumento Natural como a mais adequada, já que os principais atributos que motivam a proteção da área estão atrelados a raridade de elementos do meio natural, geológicos e ecológicos, e a beleza cênica da paisagem. Cabe destacar que tal categoria de unidade de conservação não exige a desapropriação da área, desde que garantida a compatibilidade dos usos com a manutenção das características que motivaram a proteção (Brasil, 2000), fato que torna o processo de criação muito mais rápido e simplificado.

Cabe ainda mencionar que Pereira et al. (2008) e Couto e Figueiredo (2019) consideram o SNUC um meio eficiente para a proteção do patrimônio geomorfológico. Pereira et al. (2008) mencionam como principal argumento a destinação de $0,5 \%$ do valor de empreendimento de significativo impacto ambiental para a criação ou manutenção de unidades de conservação (Brasil, 2000). Este mecanismo permite viabilizar financeiramente as unidades de conservação e, apesar de sua importância, a experiência mostra que a utilização deste recurso para a criação de novas áreas protegidas é pouco frequente, prevalecendo a destinação para manutenção das já existentes.

Já no caso do Cerro dos Porongos, o órgão responsável pelo patrimônio na esfera federal iniciou, há mais de uma década, processo de tombamento com a classificação de patrimônio natural (IPHAN, 2020). No entanto, não constam informações sobre o andamento do processo, não havendo, até ao momento presente, nenhum instrumento de proteção patrimonial, tombamento ou registro incidindo sobre o local. Ainda no âmbito federal, foi elaborado Inventário Nacional de Referência Cultural (INRC) Massacre de Porongos. Os bens alvos deste instrumento, o qual tem sua definição apresentada abaixo, podem vir a ser tombados ou registrados:

O Inventário Nacional de Referências Culturais (INRC) é uma metodologia de pesquisa desenvolvida pelo Iphan para produzir conhecimento sobre os domínios da vida social aos quais são atribuídos sentidos e valores e que, portanto, constituem marcos e 


\begin{abstract}
referências de identidade para determinado grupo social. (...) A delimitação da área do Inventário ocorre em função das referências culturais presentes num determinado território. Essas áreas podem ser reconhecidas em diferentes escalas, ou seja, podem corresponder a uma vila, a um bairro, a uma zona ou mancha urbana, a uma região geográfica culturalmente diferenciada ou a um conjunto de segmentos territoriais. (IPHAN, 2020c)
\end{abstract}

No Quadro I é apresentada uma síntese das características de ambos os sítios onde é possível comparar de maneira objetiva as duas situações:

Quadro I: Síntese comparativa dos aspectos relativos a conservação das áreas.

\begin{tabular}{|c|c|c|c|}
\hline \multicolumn{2}{|c|}{ Aspectos } & Cerro do Jarau & Cerro dos Porongos \\
\hline \multirow{2}{*}{$\begin{array}{l}\text { Critério biológico } \\
\text { (MMA, 2007) }\end{array}$} & Prioridade & Extremamente Alta & Extremamente Alta \\
\hline & Importância & Muito Alta & Extremamente Alta \\
\hline \multirow{2}{*}{$\begin{array}{l}\text { Processo em } \\
\text { andamento }\end{array}$} & Esfera & Ambiental & Cultural \\
\hline & Instância & Estadual & Federal \\
\hline \multicolumn{2}{|c|}{ Valores intrínsecos } & $\begin{array}{l}\text { Geológico; Geomorfológico } \\
\text { Histórico; Cultural; } \\
\text { Identitário; Paisagístico; } \\
\text { Ecológico; Turístico; } \\
\text { Educativo; Científico; }\end{array}$ & $\begin{array}{c}\text { Geomorfológico } \\
\text { Histórico; Cultural; } \\
\text { Identitário; Étnico; Simbólico; } \\
\text { Paisagístico; Educativo; } \\
\text { Científico; }\end{array}$ \\
\hline \multicolumn{2}{|c|}{ Uso atual } & $\begin{array}{c}\text { Turístico; Educativo; } \\
\text { Científico; }\end{array}$ & $\begin{array}{l}\text { Celebrações Culturais; } \\
\text { Educativo; Científico; }\end{array}$ \\
\hline \multicolumn{2}{|c|}{ Situação de proteção } & Sujeito a Degradação & Sujeito a Degradação \\
\hline
\end{tabular}

Ainda no que se refere à proteção ambiental, cabe destacar que o predomínio do enfoque biológico em relação ao geológico/geomofológico pode ser constatado quando são analisados os instrumentos de proteção vigentes, a exemplo de zoneamentos para atividades passíveis de licenciamento. Em tais instrumentos a restrição quanto à implantação de empreendimentos em morros testemunhos e afloramentos rochosos justifica-se por estes locais serem habitats propícios à geração de endemismos da flora e fauna. Cabe ainda considerar que, quando associados a litologias sedimentares, os cerros correspondem a feições do relevo mais suscetíveis a processos erosivos, sendo um importante indicativo de fragilidade ambiental.

Diferentemente de Pereira et al. (2008) e Couto e Figueiredo (2019), Delfhim (2009) considera que a efetiva proteção dos valores históricos, simbólico e identitários de locais como o Cerro dos Porongos, exigem uma gestão por parte de órgãos da esfera cultural e não por meio da criação de unidade de conservação no sistema de proteção ambiental. Tal apontamento se justifica diante da dificuldade de abertura para 0 tratamento de questões culturais no âmbito do sistema ambiental atualmente vigente. Esta consideração evidencia as dificuldades práticas de garantir a efetiva proteção do patrimônio, apontando para a necessidade de uma abordagem integrada.

Diante desta perspectiva, a discussão vislumbra uma nova problemática para a efetiva proteção dos valores patrimoniais: para além da qualificação do SNUC com relação à efetiva valoração e conservação do patrimônio geomorfológico, é preciso avançar na busca de formas mais eficientes de assegurar a proteção do patrimônio. Em locais que evidenciam forte associação de valores culturais aos elementos naturais, a 
exemplo dos sítios trazidos no presente artigo, os sistemas atualmente vigentes apresentam limitações que dificultam a consolidação de práticas de proteção do patrimônio, evidenciando a necessidade de uma abordagem mais abrangente do tema.

\section{Conclusões}

Por meio das discussões apresentadas, o presente trabalho buscou demonstrar a intrínseca relação entre patrimônios classificados como naturais, mais especificamente o patrimônio geomorfológico, e patrimônios classificados como culturais e buscou problematizar a necessidade de construção de políticas públicas mais plurais e interdisciplinares, que assegurem a efetiva proteção destes sítios de interesse para a sociedade. Cabe ressaltar que o presente artigo não teve a pretensão de esgotar o assunto e sim trazer à luz do debate uma temática urgente e necessária tanto para o meio acadêmico quanto para os órgãos públicos.

O valor intrínseco dos morros testemunhos e cerros, no contexto cultural e geológico/geomorfológico do Rio Grande do Sul, ainda necessita ser efetivamente incorporado nas políticas públicas e no planejamento territorial a fim de assegurar uma proteção mais abrangente contemplando as formas de relevo. O Cerro do Jarau e o Cerro dos Porongos são exemplos de sítios que ilustram objetivamente a artificialidade das divisões entre patrimônio natural e cultural, e apesar da multiplicidade de seus valores, continuam sem efetiva proteção e suscetíveis a intervenções.

Para além da abordagem em escala local, a discussão levantada por meio dos dois exemplos trazidos ao longo deste artigo busca contribuir para a premente discussão a respeito da articulação conceitual entre cultura e natureza no contexto da proteção de áreas com valores diversos, visando também fomentar maiores reflexões sobre como classificações artificiais podem impactar na proteção e gestão de inúmeros sítios de valor patrimonial para diferentes grupos que compõem a sociedade. Diante do exposto, o artigo evidencia ainda a necessária aproximação entre os órgãos ambientais e culturais, visando qualificar os processos de reconhecimento e gestão da pluralidade destes patrimônios, seja pela aplicação de instrumentos legais já vigentes, seja pela discussão de novos caminhos.

\section{Agradecimentos}

As autoras agradecem as valiosas contribuições dos avaliadores, além do geógrafo da Divisão de Unidades de Conservação da SEMA, Ailton Giovane Mandião, pelo acesso a informações e discussões na busca de perspectivas sobre o assunto.

\section{Bibliografia}

Ab'Sáber, A. N. (1970). Províncias geológicas e domínios morfoclimáticos no Brasil. Geomorfologia. São Paulo: Universidade de São Paulo, 20, 1-26.

Ab'Sáber, A. N. (2003). Os domínios de natureza no Brasil: potencialidades paisagísticas. São Paulo: Ateliê Editorial. 
Alves, F. da S. (2012). Fitogeografia da região do Jarau - Quaraí/RS. Tese de Doutorado em Engenharia Florestal, Universidade Federal de Santa Maria, Santa Maria, Brasil

Bilhar, J. D., Midugno, R., Silva, R. F., Kormann, T. C. (2019). Cerro dos Porongos: um lugar de memórias. In: Anais do V Simpósio Brasileiro De Patrimônio Geológico: (Re)Pensar o Patrimônio Geológico para o Geoturismo e Desenvolvimento Local (pp. 20-21). Crato: Universidade Federal do Cariri.

Brasil (1937). Decreto-Lei $n^{\circ}$ 25, de 30 de novembro de 1937. Organiza a proteção do Patrimônio Histórico e Artístico Nacional. Disponível em 13/05/2020 em: http://www.planalto.gov.br/ccivil 03/decreto-lei/del0025.htm

Brasil (1988). Constituição da República Federativa do Brasil de 1988. Disponível em $30 / 01 / 2020$

em:

http://www.planalto.gov.br/ccivil $03 /$ constituicao/constituicaocompilado.htm

Brasil (2000). Institui o Sistema Nacional de Unidades de Conservação da Natureza. Lei $n$. 9.985, de 18 de julho de 2000. Disponível em 22/08/2012 em: http://www.mma.gov.br/estruturas/sbf dap cnuc2/ arquivos/snuc.pdf

Brilha, J. (2005). Património Geológico e Geoconservação: A Conservação da Natureza na sua Vertente Geológica. Braga: Palimage Editores.

Brilha, J. (2016). Inventory and quantitative assessment of geosites and geodiversity sites: a review. Geoheritage, 8(2): 119-134.

Castro, A. R. S. F., Mansur, K. L., Carvalho, I. S. (2018). Reflexões sobre as relações entre geodiversidade e patrimônio: um estudo de caso. Terr@Plural, 12(3): 383-403. Disponível em 30/11/2020 em: https://revistas.apps.uepg.br/index.php/tp/article/view/12067

Carcavilla, L., Durán, J.J., López-Martínez, J. (2008). Geodiversidad: concepto y relación con el patrimonio geológico. Geo-Temas, 10, 1299-1303. Disponível em 23/01/2020 em: https://www.igme.es/patrimonio/descargas/concepto Geodiversidad.pdf

Chomenko, L., Bencke, G. A. (2016). Nosso Pampa desconhecido. Porto Alegre: Fundação Zoobotânica do Rio Grande do Sul, 2016.

Coratza, P., Hobléa, F. (2018). The specificities of geomorphological heritage. In: Reynard, E., Brilha, J. (Orgs.). Geoheritage: Assessment, Protection and Management (pp. 87-106). Amsterdam: Elsevier.

Couto, M. S., Figueiredo, C. A. A. (2019). Geoconservação em Monumentos Naturais no Brasil. Physis Terrae: Revista Ibero-Afro-Americana de Geografia Física e Ambiente, 2, 231-248. Disponível em 22/05/2020 em: https://revistas.uminho.pt/index.php/physisterrae/article/view/2269

Crósta, A. P., Lourenço, F. S., Priebe, G. H. (2010). Cerro do Jarau, Rio Grande do Sul: a possible new impact structure in southern Brazil. In: Gibson, R. L., Reinold, W. U. (Orgs.) Large Meteorite Impacts and Planetary Evolution IV. The Geological Society of America Special Paper, 465, 173-190.

Delphim, C. F. M. (2009). Paisagens do Sul: Pareceres de Carlos Fernando de Moura Delphim sobre bens patrimoniais do Rio Grande do Sul. Porto Alegre: IPHAN.

Fontana, V., Reed, S. (2019). Mais degradado que o Cerrado e Amazônia, Pampa é o bioma menos protegido do país. National Geographyc. Disponível em 31/01/2020 em: 
https://www.nationalgeographicbrasil.com/meio-ambiente/2019/10/degradacao-cerradoamazonia-pampa-bioma-brasil-rio-grande-do-sul-vegetacao?fbclid=IwAR2n2Fy3JBycZ0s3K6KIK a DOGzvKEGJNaNNjLf1vv7sK3 xfJO8 TmJ0

Guerra, A. J. T. (1975). Dicionário geológico-geomorfológico. (4th ed.). Rio de Janeiro: IBGE.

IBGE (2004). Mapas de biomas do Brasil, primeira aproximação. Formato shapefile. Rio de Janeiro. Disponível em 14/04/2018 em: https://www.ibge.gov.br/geociencias/cartas-emapas/informacoes-ambientais/15842-biomas.html?=\&t=downloads

IPHAN (2009). Estabelece a chancela da Paisagem Cultural Brasileira. Portaria $n^{\circ}$ 127, de 30 de abril de 2009. Diário Oficial União. Disponível em 21/06/2020 em: https://www.normasbrasil.com.br/norma/portaria-127-2009 214271.html

IPHAN (2020a). Conjuntos Urbanos Tombados Nordeste - Lençóis - BA. Disponível em 28/05/2020 em: http://portal.iphan.gov.br/pagina/detalhes/115

IPHAN (2020b). Bens Tombados. Disponível em 24/05/2020 em: http://portal.iphan.gov.br/pagina/detalhes/126

IPHAN (2020c). Inventário Nacional de Referências Culturais (INRC). Disponível em 28/05/2020 em: http://portal.iphan.gov.br/pagina/detalhes/685/

Kuplich, T. M., Capoane, V., Costa, L. F. F. (2018). O avanço da soja no Bioma Pampa. Boletim Geográfico do Rio Grande do Sul, 31, 83-100. Disponível em 26/02/2020 em: https://revistas.fee.tche.br/index.php/boletim-geografico-rs/article/view/4102

Melo, I. (2020). Veio do espaço: você sabe como se formou o Cerro do Jarau, famoso por lenda e da Era dos dinossauros? Disponível em 31/01/2020 em: https://gauchazh.clicrbs.com.br/comportamento/noticia/2020/01/veio-do-espaco-vocesabe-como-se-formou-o-cerro-do-jarau-famoso-por-lenda-e-da-era-dos-dinossaurosck62i88t10d3c01mvyy8i7nsr.html

MMA (2007). Portaria MMA no 9, de 23 de janeiro de 2007. Disponível em 26/02/2020 em: https://www.icmbio.gov.br/cepsul/images/stories/legislacao/Portaria/2007/p mma 09200 7 areaprioritariaparabiodiversidade revgd p 126 2004.pdf

Overback, G. E. et al. (2009). Os campos sulinos: um bioma negligenciado. In: Pillar, V. de P., Müller, S. C., Castilhos, Z. M. de S., Jacques, A. V. A. (Eds.). Campos Sulinos: conservação e uso sustentável da biodiversidade. (pp. 26-41). Brasília: MMA. Disponível em 29/04/2018 em: http://ecoqua.ecologia.ufrgs.br/arquivos/Livros/CamposSulinos.pdf

Pereira, R. F., Brilha, J., Martinez, J. E. (2008). Proposta de enquadramento da geoconservação na legislação ambiental brasileira. Memórias e notícias: Publicação do Departamento de Ciências da Terra e do Museu de Mineralogia e Geologia, 3, 491-499. Disponível em 09/04/2020 em: http://sigep.cprm.gov.br/destaques/Pereira Brilha Martinez GDCL 2008.pdf

Pereira, A., Martins, B. (2018). Interações entre o patrimônio geomorfológico e a paisagem cultural da Serra do Alvão: a perspectiva da Geomorfologia Cultural. In: Anais do II Encontro Luso-Afro-Americano de Geografia Física e Ambiente (1167-1173). Guimarães: Universidade do Minho.

Pesavento, S. J. (1982). História do Rio Grande do Sul. (2th ed.). Editora Mercado Aberto: Porto Alegre. 
Reynard, E., Giusti, C. (2018). The Landscape and the Cultural Value of Geoheritage. In: Reynard, E., Brilha, J. (Eds.). Geoheritage: Assessment, Protection and Management (pp. 147-166). Amsterdam: Elsevier.

Ribeiro, R. W. (2016). Rio de Janeiro: paisagens cariocas entre a montanha e o mar. Santos: Editora Brasileira de Arte e Cultura; Brasília: UNESCO.

Salaini, C. J., Graeff, L. (2011). A respeito da materialidade do patrimônio imaterial: o caso do INRC Porongos. Revista Horizontes Antropológicos, 36, 171-195. Disponível em 21/03/2019 em: https://www.scielo.br/pdf/ha/v17n36/v17n36a08.pdf

Sánchez, J. P., Garcia, M. da G. M. A. (2013). A cratera de impacto do Cerro do Jarau-RS, Brasil: Uma abordagem geoturística. In: Anais do II Simpósio Brasileiro de Patrimônio Geológico, 2013. (p. 102-110). Ouro Preto: Universidade Federal de Ouro Preto.

Sánchez, J. P., Simões, L. S. A., Martins, L. E. B. (2014). Estratigrafia e estrutura do Cerro do Jarau: nova proposta. Brazilian Journal of Geology, 44(2): 265-276. Disponível em 25/02/2020 em: https://www.scielo.br/pdf/bjgeo/v44n2/2317-4889-bjgeo-44-02-00265.pdf

SEMA - Secretaria Estadual do Meio Ambiente do Rio Grande do Sul (2013). Proposta de criação de unidade de conservação na região do Cerro do Jarau, município de Quaraí, Rio Grande do Sul. (Parecer Técnico). Porto Alegre.

Silva, R. G. P., Mansur, K. L., Castro, A. R. S. F. (2020). Consolidação da geodiversidade como patrimônio e o valor geológico dos monumentos do Rio de Janeiro. Anuário do Instituto de Geociências - UFRJ, 43(3): 488-497. Disponível em 25/10/2020 em: https://revistas.ufri.br/index.php/aigeo/article/view/36435

Suertegaray, D. M. A. (2018). Geografia Física e Geomorfologia: uma releitura. (2th ed.). Porto Alegre: Compasso.

Vieira, L. de F. dos S. (2014). A valoração da beleza cênica da paisagem do bioma pampa do Rio Grande do Sul: proposição conceitual e metodológica. Tese de doutorado em Geografia, Universidade Federal do Rio Grande do Sul, Porto Alegre, Brasil. Disponível em 19/10/2017 em: https://lume.ufrgs.br/handle/10183/106341

Wiggers, M. M (2015). O Bioma Pampa como Patrimônio Natural, Ambiental e Paisagístico. O futuro do Bioma Pampa, Centro Cultural da Universidade Federal do Rio Grande do Sul, 2015. (Palestra). Porto Alegre: Universidade Federal do Rio Grande do Sul.

Artigo recebido em / Received on: 24/07/2020

Artigo aceite para publicação em / Accepted for publication on: 17/04/2021 